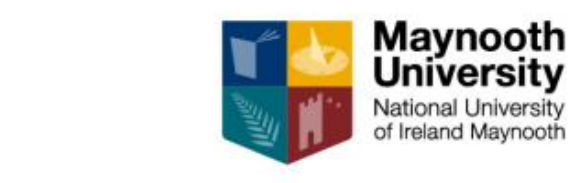

Department of Economics Finance \& Accounting

Working Paper N299-20

\title{
Does retirement affect voluntary work provision? Evidence from England, Ireland and the U.S.
}

\author{
Peter Eibich ${ }^{1}$, Angelo Lorenti ${ }^{1}$ and Irene Mosca ${ }^{2}$
}

\author{
1 Max Planck Institute for Demographic Research, Rostock, Germany \\ E-mail: eibich@demogr.mpg.de, lorenti@demogr.mpg.de \\ 2 Maynooth University, Ireland \\ E-mail: irene.mosca@mu.ie
}

\begin{abstract}
Voluntary work is an important contribution for many non-profit organizations, such as charities, political and religious organizations. Older individuals make up a sizable share of the volunteer workforce, and volunteering is often regarded as an example of "active ageing". In this study, we examine whether retirement has a causal effect on the frequency of voluntary work provision in three English-speaking countries - England, Ireland and the U.S. We draw on data from the ELSA, TILDA and HRS studies and employ a harmonised approach in the empirical analysis. We use eligibility ages for old age pensions in an instrumental variable estimation to address potential confounding. We find that retirement increases the frequency of voluntary work provision in all three countries, especially among men. This suggests that labour market policies aimed at increasing labour force participation at older ages might have unintended consequences for the size of the volunteer workforce.
\end{abstract}

JEL codes: J22; J26

Keywords: retirement, voluntary work, instrumental variables 


\section{Introduction}

Voluntary work provision contributes to the functioning of many societies around the globe. Many non-profit organizations - such as charities, hospitals, care homes, sports clubs or religious and political groups - rely on volunteers for their activities. Voluntary work, whether provided formally through an organization or informally between neighbours, can help maintain or even improve social cohesion (Komp et al. 2012). Volunteers benefit from their engagement as well by engaging in an activity that is perceived as meaningful and enhances their self-esteem (Okun et al. 1998). Volunteering is associated with better health and wellbeing (Luo et al. 2019; Nazroo 2015) and is thus considered part of an “active ageing” strategy (Chiao 2019; Luo et al. 2019).

Older individuals form a vital part of the volunteer workforce. In the UK, Ireland and the U.S., levels of engagement in voluntary work among individuals aged 65 and above are comparable to engagement levels across the whole population. The participation rate in formal volunteering for the adult population as a whole was reported at $41 \%, 28 \%$ and $25 \%$, respectively, compared to rates of 37\% (UK), 28\% (Ireland) and 24\% (U.S.) among the over 65s (Bureau of Labor Statistics 2016; Central Statistics Office 2015; Office for National Statistics 2017).

Academic studies have proposed activity substitution (Chambré 1984; Mutchler et al. 2003; Tang 2015) to explain the sustained engagement of older people in voluntary work, despite declining health. As individuals approach retirement age, they substitute paid employment with voluntary work. However, across the lifespan individuals have complex motivations for volunteering, including career advancement (Okun et al. 1998). Many volunteers combine employment and voluntary work throughout young adulthood and middle age. Thus, activity complementarity has been proposed as a competing hypothesis (Mutchler et al. 2003; Tang 2015). According to this second hypothesis, voluntary work provision decreases after retirement. Whether retirement affects voluntary work provision positively or negatively thus remains an empirical question - one that has become more salient due to population ageing.

The workforce in many high-income countries is expected to shrink due to population ageing. Policy makers across the world have enacted reforms to increase labour force participation at older ages and extend working lives (Dudel et al. 2018; Dudel and Myrskylä 2017) to mitigate expected labour force shortages, e.g., by raising the state pension age. If older individuals substitute employment and voluntary work, then such reforms could lead to an 
unintended reduction of the volunteer workforce. In contrast, activity complementarity would imply that these reforms have beneficial effects on voluntary work provision.

This comparative study considers the causal impact of retirement on voluntary work provision in England, Ireland and the U.S. For the analysis, we use data covering the period 2009-2017 from three longitudinal ageing studies - the English Longitudinal Study on Ageing (ELSA), The Irish Longitudinal Study on Ageing (TILDA) and the U.S. Health and Retirement Study (HRS). We conduct a harmonized analysis to facilitate comparisons across countries. We use age thresholds for state pensions and Social Security benefits as instrumental variables to address selection into retirement. The results of our analysis indicate remarkable consistency in the relationship between retirement and voluntary work in all three countries: retirement leads to a substantial increase in the probability to volunteer, especially among men.

This is one of the first studies in the literature to provide evidence of a causal effect by addressing the endogeneity of the retirement decision. Laferrère (2016) follows a similar approach, but estimates pooled effects of retirement across 10 continental European countries, while we provide separate analyses for England, Ireland and the U.S. We also extend the analysis by considering the role of previous voluntary work engagement, and by characterizing the complier population.

In the following section, we discuss theoretical approaches that can motivate the competing hypotheses of activity substitution and activity complementarity, and we review evidence from previous empirical studies. In section 3, we provide an overview over the data and measures used in our analysis. Section 4 describes the econometric methods. The results are reported in section 5, and we discuss our findings in section 6 . Section 7 concludes the study.

\section{Theoretical Background}

\subsection{Hypotheses}

Two competing hypotheses have been proposed in the literature on retirement and voluntary work provision (Chambré 1984; Mutchler et al. 2003; Tang 2015). The substitution hypothesis posits that paid work and voluntary work can be considered as substitutes, i.e., a decrease in paid work leads to an increase in voluntary work provision, and vice versa. In contrast, the complementarity hypothesis considers paid work and volunteering to be complements, hence a decrease in paid work would be accompanied by a decrease in voluntary 
work. These two hypotheses can be motivated from various theoretical perspectives. In the following, we provide a brief overview of these theories and discuss the empirical evidence.

\subsubsection{Activity substitution}

Substitution between paid work and volunteering might be a consequence of opportunity costs of time investments, which are a part of many economic models on human capital and health capital (e.g., Galama et al. 2013; Grossman 1972). Since individuals only have a fixed "time budget" available, they face trade-offs between time investment in market work and investments in non-market activities. Before retirement, individuals rely on market work to finance their consumption, and thus the opportunity costs of alternative time investments are relatively high. Retirement relaxes this constraint, since retirees finance their consumption through their pension rather than paid work. Thus, retirement enables older individuals to spend more time on other activities, e.g., voluntary work.

A similar conclusion can be derived from the resource perspective (Lancee and Radl 2014). Engagement in voluntary work might require the presence of certain resources, e.g., time, which enable voluntary work provision. If retirement increases the availability of these resources, we would expect that retirees volunteer more.

An alternative motivation for activity substitution is provided by role theory (Mutchler et al. 2003). The transition into retirement is associated with a loss (or shedding) of previously held roles. As older individuals seek continuity over their life course (Atchley 1989), they look towards substituting their previous role as employee or worker with new roles, e.g., volunteer.

Closely related to this is the interest perspective, which emphasises the motives and aims of volunteers. As volunteering is associated with better health and well-being (Chiao 2019; Luo et al. 2019; Mosca and Wright 2017), older adults might decide to volunteer as part of an "active ageing" strategy to maintain their health in retirement. For example, voluntary work might offset the loss of social contacts and social participation associated with retirement (Smith 2010), and therefore retirement might motivate older adults to provide (more) voluntary work.

\subsubsection{Activity complementarity}

The interest perspective (Lancee and Radl 2014) can also motivate the complementarity hypothesis. Individuals might volunteer for work-related reasons (Okun et al. 1998; Wilson and Musick 1997), e.g., to develop relevant skills or establish contacts. For individuals leaving 
the labour force, such considerations become less relevant, and they might therefore be less motivated to volunteer.

Finally, the resource perspective is similarly ambiguous. If retirement reduces the availability of resources enabling voluntary work provision, then new retirees might reduce their engagement in voluntary work. For example, if retirement negatively impacts health (Heller-Sahlgren 2017), then retirees might have fewer capacities to volunteer. Likewise, a decline in social participation upon retirement (Smith 2010) might imply that retirees are offered fewer opportunities to volunteer.

Consequently, the effect of retirement on voluntary work provision is ultimately an empirical question. The relevant theoretical frameworks provide support for both the substitution hypothesis and the complementarity hypothesis, and it is unclear which of these potential mechanisms dominates. Before summarising the empirical evidence, we briefly discuss how these theoretical mechanisms apply to different subgroups of the population.

\subsection{Heterogeneity between individuals}

The relevance of the mechanisms outlined above likely differs between individuals. For example, labour force participation at older ages is lower for women than for men (Gilfillan and Andrews 2010). Older women do not necessarily face fewer time constraints than men. The majority of home production is done by women, and this division of labour does not change upon retirement (Bonsang and van Soest 2020; Stancanelli and van Soest 2012). Moreover, older women provide more informal care (Schmitz and Westphal 2015) and childcare (Eibich and Siedler 2020) than men. However, retirement does not affect the demand for these activities. Therefore, the change in time costs upon retirement is likely (on average) larger for men than for women, hence retirement might have a stronger effect on volunteering for men than for women. Following a similar reasoning, older women might identify less with their roles as workers as they occupy a variety of different roles before retirement. Thus, the loss of their role as worker might have a smaller impact on women.

This also suggests that differences in the effects of retirement on volunteering might exist among partnered individuals, depending on how family and work roles are distributed between partners. Partnered individuals might prefer to spend additional time on joint activities (Stancanelli and van Soest 2012, 2016), which would reduce the potential impact of retirement on voluntary work. The partner might also represent a resource that facilitates voluntary work provision, e.g., through an extended social network (Lancee and Radl 2014). On the other hand, 
a specialization perspective (Becker 1981) suggests that one of the partners might engage in volunteering while the other spends the additional time in different activities.

Highly educated individuals are more likely to identify with their occupational role than lower educated individuals, and consequently they might be more inclined to seek continuity through voluntary work provision. Moreover, if education is a resource that facilitates voluntary work provision (e.g., by allowing volunteers to engage in more demanding and more satisfying tasks), then higher educated individuals might similarly be more inclined to engage in voluntary work after retirement.

Finally, the literature has highlighted the importance of previous engagement in voluntary work as one of the most important predictors of voluntary work provision (Di Gessa and Grundy 2016; Erlinghagen 2010; Mutchler et al. 2003). Individuals providing voluntary work might choose to expand their engagement and provide more intensive voluntary work. In contrast, individuals who newly take up volunteering after retirement might (initially) volunteer fewer hours or less frequently. Thus, we should distinguish between changes at the extensive margin (i.e., the probability to volunteer) and the intensive margin (i.e., the frequency of voluntary work provision). Moreover, retirees might find it easier to expand their existing engagement than to engage in new activities, which would imply that the impact of retirement is concentrated at the intensive margin.

\subsection{Empirical evidence}

Empirical evidence on the causal effect of retirement on voluntary work provision is scarce. While cross-sectional associations have long been documented in the literature (Caro and Bass 1997; Chambré 1984), these findings are likely biased by unobserved confounders. Longitudinal data can be used to observe the transition from work to retirement and associated changes in voluntary work provision, and panel data methods can be used to adjust for observed and unobserved time-invariant confounders. Yet, there are very few studies that have examined the impact of retirement on volunteering with longitudinal data.

Mutchler et al. (2003) use the 1986 and 1989 waves of the “Americans' Changing Lives" survey to document changes in formal and informal voluntary work provision following retirement in the U.S. They report an increase in formal voluntary work provision, particularly for individuals who were not previously engaged in voluntary work. Their results do not indicate any effect on informal voluntary work. Erlinghagen (2010) uses data from the German Socio-Economic Panel Study between 2001 and 2005 to examine formal and informal voluntary work provision. He finds modest effects of entry into retirement on the likelihood to 
take up voluntary work. He notes that these effects are dominated by the effects of previous engagement in voluntary work provision. Di Gessa and Grundy (2016) use two waves of data from the Survey of Health, Ageing and Retirement in Europe (SHARE) for Denmark, France and Italy (2004-2007) and two waves of ELSA data for England (2002-2005). They consider formal and informal voluntary work provision and find that retirement is associated with an increase in formal voluntary work provision (Denmark and France) and with informal volunteering (England and Italy). Tang (2015) uses HRS data from 1998-2008 for the U.S. She uses latent class analysis to form employment profiles over time, and finds that the transition from work to retirement increases the time dedicated to voluntary work (i.e., the intensive margin), but has no effects on engagement or disengagement in voluntary work (i.e., the extensive margin).

A common limitation of these studies is that they do not address the endogeneity of the retirement transition. Most importantly, poor health is one of the major determinants of retirement (McGarry 2004), as well as of reduced engagement in volunteering (Komp et al. 2012). If these health shocks occur between survey waves and cause individuals to retire, then it is not sufficient to control for health status observed at the time of the survey, since individuals might have (partially) recovered from such shocks. If unaccounted for, these health shocks would bias the estimates of retirement effects downwards.

The study by Laferrère (2016) is the only study in the literature to address this bias. Using data from SHARE for the years 2004-2011, she estimates the effect of retirement on several different social activities, including voluntary work provision. She addresses the endogeneity of retirement by using state pension ages for early and normal retirement in an instrumental variable (IV) analysis. Her results indicate that retirement leads to an increase in voluntary work provision.

\section{Data}

\subsection{Overview and Sample Selection}

We use data from three longitudinal ageing studies - the English Longitudinal Study of Ageing (ELSA), The Irish Longitudinal Study on Ageing (TILDA), and the U.S. Health and Retirement Study (HRS). All three studies are designed to survey individuals aged 50 and above living in private households as well as their cohabiting partners, irrespective of age. Detailed information on the participants' economic circumstances, social interactions and health status is collected. Survey participants are interviewed every two years. Data collection 
in HRS started in 1992. ELSA and TILDA were designed to be closely compatible, with data collection starting in 2002 (ELSA) and 2009 (TILDA), respectively. For a detailed description of these studies see Sonnega et al. (2014), Taylor et al. (2007) and Kearney et al. (2011).

To facilitate comparisons across studies, we restrict our analysis to the period 2009 to 2016, in which data are available for all three studies. In particular, we use ELSA waves 5-8 (2010-2017), TILDA waves 1-4 (2009-2016) and HRS waves 10-13 (2010-2016). In all three datasets, we include all observations for individuals aged 50-79, i.e., around retirement age. We exclude individuals who report to have never done any paid work. Our final analytical samples consist of three unbalanced panels of 8,418 individuals (25,578 observations) for ELSA, 6,946 individuals (20,150 observations) for TILDA and 21,255 individuals $(60,882$ observations) for HRS. The average number of observations per individual is 3 in ELSA and 2.9 in TILDA and HRS.

\subsection{Variable Definitions}

\subsubsection{Outcomes}

Voluntary work provision is assessed differently in the three studies. Since information on informal voluntary work (i.e., help provided to neighbours, friends or family) is not available in all studies, we focus on formal volunteering (i.e., voluntary work provided in the context of an organization) in the analysis of this paper. In the ELSA study, we use a question for which respondents are asked: "Overall, about how often over the last 12 months, since [date one year ago], have you generally done something to help this/these organisation(s) remember to include any time spent at home or elsewhere helping this/these organisation(s)."1 The possible answers include "at least once a week", "less than once a week but at least once a month”, “less often”, “one-off activity”.

In the TILDA study, respondents are asked: "How often, if at all, do you do any of the following activities?”. A list of activities is presented and one of the entries is "do voluntary work”. Potential answers include "daily/almost daily”, "once a week or more”, "twice a month or more”, “about once a month”, “every few months”, “about once or twice a year”, “less than once a year”, and “never".

The HRS study asks respondents: "Have you spent any time in the past 12 months doing volunteer work for religious, educational, health-related, or other charitable organizations?”

\footnotetext{
1 The previous question asks about the kind of voluntary work provided, and refers to "groups, clubs or organisations“.
} 
If they respond with "yes”, they are then asked: “Altogether, would you say the time amounted to less than 100 hours, more than 100 hours, or what?”. Possible answers are "less than 100 hours”, “about 100 hours”, and “more than 100 hours”. If they respond with "more than 100 hours", the same question is repeated using a threshold of 200 hours. If they respond with "less than 100 hours", the same question is repeated using a threshold of 50 hours.

Based on these questions, we construct three binary indicators measuring the frequency of voluntary work provision across studies. For the ELSA and TILDA data, these indicators are: “any volunteering”, “at least monthly volunteering”, and “at least weekly volunteering”. “Any volunteering” captures whether respondents reported doing any voluntary work, including one-off activities or volunteering less than once a year. For HRS data, the three indicators are: "any volunteering”, “50+ hours of volunteering per annum (р.a.)” and " $100+$ hours of volunteering p.a.”. It is important to note that in all the studies, the three categories are not mutually exclusive. By definition, someone who volunteers at least weekly also volunteers at least monthly and provides “any” voluntary work.

\subsubsection{Definition of Retirement}

Individuals can exit the labour market for reasons other than old-age retirement, such as unemployment, home making and sickness. There is no clear consensus in the literature on whether such transitions should be considered as equivalent to retirement, partly because this depends on the potential mechanisms under consideration as well as the institutional setting. As a consequence, several different definitions of retirement have been adopted in the literature. Yet, a recent comparative study on the health effects of retirement found that such differences had little impact on the conclusions (Nishimura et al. 2018).

We are primarily interested in retirement as an exit from the labour market. Therefore, our definition of retirement is based on self-reported labour force status. We define individuals as retired if they report their labour force status as retired, semi-retired or homemaker, whereas we define employed, self-employed, unemployed, permanently sick or disabled individuals as well as those reporting to be in education or training as not retired.

We consider homemakers to be retired, since they do not have to trade-off paid activities against non-market activities, instead their time is spent entirely on non-market activities. In contrast, unemployed individuals are likely looking to re-enter paid employment, and might thus spent some of their time on the job search or training activities. Finally, permanently sick or disabled individuals might be limited in their ability to participate in 
certain non-market activities, such as voluntary work, and thus their exit from the labour market cannot be considered equivalent to retirement.

We assess the sensitivity of our findings to the retirement definition by exploring alternative definitions, in which we treat homemakers as not retired and unemployed as well as permanently sick or disabled individuals as retired, respectively.

\subsubsection{State Pension Ages}

We use age thresholds for state pension eligibility as instrumental variables for retirement (see section 4 for details). We construct binary indicators, which take on the value of 1 if an individual is above the age threshold for pension eligibility in year $t$, and 0 otherwise.

In England, the eligibility age for the basic state pension was 65 for men in the period studied in this paper. For women, the eligibility age increased from 60 to 63 . These incremental changes were based on the date of birth. We use an indicator (generated by the Institute for Fiscal Studies and provided as part of the ELSA data) on whether individuals had reached the relevant state pension age at the time of the interview.

In Ireland, the contributory and non-contributory state pensions are currently paid from age 66. However, until December 2013, individuals were also entitled to the so-called "transition state pension" when they reached age 65, provided that they had paid enough contributions. This pension was paid only for one year and individuals were then automatically transferred to contributory state pension when they reached age 66. This means that, in practice, those who had paid enough social insurance qualified for the contributory state pension at age 65. Therefore, in the TILDA data we set the age threshold that identifies whether individuals have reached the state pension age at the time of the interview at 65 in the first two waves (2009/10 and 2012/2013) and at age 66 in the third and fourth waves (2014/2015 and 2016).

For the U.S., we use eligibility ages for Social Security benefits as instrumental variables, following the approach adopted by Bonsang et al. (2010, 2012). Specifically, we generate binary indicators for whether individuals exceed the age thresholds of 62 (early retirement through the Social Security program) or 65 (normal retirement under the Social Security program). We also adjust the threshold at 65 to account for pension reforms, which increased this threshold incrementally from 65 to 67 for individuals born from 1937 onwards. 


\subsubsection{Covariates}

These age thresholds can only be considered valid instruments for retirement conditional on age (see section 4.1 for a detailed discussion). We therefore include a quadratic age trend in all regression models.

While the validity of our instrumental variable approach does not depend on the inclusion of other covariates associated with voluntary work provision and retirement, we nevertheless adjust for selected additional characteristics. Including predetermined covariates can increase the precision of the estimates by reducing random variation, and by comparing estimates from IV models with and without covariates we can assess the validity of our approach, since the inclusion of covariates should not affect the point estimates in our IV model substantially. An important caveat is that the inclusion of certain covariates might introduce a bias in our results, if these covariates act as mediators (i.e., retirement affects voluntary work provision through its effect on this covariate) or colliders (i.e., variables that are jointly determined by retirement and voluntary work provision). Therefore, we only include variables that are considered to be predetermined or unrelated to retirement.

We include education as a categorical variable, whose three categories are broadly comparable to the International Standard Classification of Education (ISCED) classification. Specifically, we distinguish between individuals with "less than secondary education", “secondary education” and “tertiary education”. We include a binary indicator for individuals who are in a partnership. For England and the U.S., we include a control variable for race/ethnicity that distinguishes between non-Hispanic whites and non-white individuals. Due to the very small sample size of non-white respondents in the TILDA data, we do not include a control variable for ethnicity for the Irish data. We also include a set of dummy variables for the survey wave to account for secular trends.

\subsection{Descriptive Evidence}

\subsubsection{Summary Statistics}

Table 1 below provides summary statistics for all three samples. In England, around $38 \%$ of individuals provide "any" voluntary work, 30\% volunteer at least monthly and 18\% volunteer at least weekly. These compare to 59\%, 32\% and 18\%, respectively, in Ireland. In the U.S., around $37 \%$ of individuals provide "any" voluntary work, 23\% volunteer for 50 or more hours per year and 15\% volunteer for 100 or more hours per year. It is worth noting that the frequencies of "at least monthly volunteering" in England and Ireland and " $50+$ hours of 
volunteering p.a.” in the U.S. are closely aligned. Similarly, the frequencies of "at least weekly volunteering" in England and Ireland and "100+ hours of volunteering p.a." in the U.S. are also aligned. The average age is 64.9 in England, 63.6 in Ireland and 64.6 in the U.S. In all the three countries, the sample is predominately female, white, in a partnership and has attended secondary education.

$<$ Table 1 about here >

\subsubsection{Labour force participation by age}

Figure 1 shows the labour force participation for individuals aged 50 to 79 in England, Ireland and the U.S., for men and women separately. We observe a decline in the share of working individuals and an associated increase in the share of retirees in all three countries. Most of the decline occurs between ages 60 and 70. The share of unemployed and permanently sick or disabled individuals remains largely constant between age 50 and 65 in England and Ireland. Beyond age 65, very few individuals report their labour force status as unemployed or permanently sick or disabled. In the U.S., the shares of unemployed and permanently sick or disabled individuals decrease steadily between age 60 and age 70 .

$<$ Figure 1 about here $>$

\subsubsection{Voluntary work provision by age}

Figures 2 and 3 show trends in voluntary work provision by age and sex in all three countries. In England and the U.S., the trend of voluntary work provision across age is almost inverse U-shaped - it initially increases between age 50 and age 65, the share of individuals volunteering peaks between ages 65 and 70, and declines thereafter. This pattern is most pronounced for English men, where the initial increase appears to be almost linear. For Ireland, we observe a similar pattern (an initial increase with a peak between age 65 and 70 and a following decline) for more frequent voluntary work (“at least monthly” or "at least weekly”). For "any voluntary work", we observe a stable trend between ages 50 and 70, with a decline afterwards. Levels of voluntary work participation are notably higher in Ireland than in England or the U.S. This is especially notable for "any voluntary work", but also for "at least weekly" and "at least monthly" volunteering levels are slightly higher. However, these differences might also be caused by differences in definitions. Due to the wording of the question, some individuals might have also reported informal voluntary work (i.e., outside of the context of organisations) in Ireland, while this was specifically excluded by the wording of the questions in ELSA and the HRS. 


\section{Methods}

\subsection{Instrumental Variables}

The decision to retire is typically made by the individual worker. While mandatory retirement rules exist in some countries (e.g., in the UK employers can mandate a so-called "employer-justified retirement age"), such rules only restrict an individual's ability to continue working beyond the normal retirement age. Workers can still decide to leave the labour market earlier. Hence, the retirement decision might be influenced by many factors, such as poor health (McGarry 2004). Omitting factors that influence an individual's retirement decision as well as their voluntary work provision will bias our estimates of the effect of retirement on volunteering. While we could control for some of these factors, e.g., spousal labour force participation or pre-existing health conditions, we cannot observe all relevant changes. For example, if an individual experiences a health shock, such as a cardiovascular event, and transitions into retirement between two survey waves, we cannot disentangle whether the health shock occurred before or after retirement.

Therefore, we use an instrumental variable approach to address the potential bias from selection into retirement. Specifically, we use the age thresholds for receipt of state pensions or Social Security benefits as instrumental variables for retirement. These age thresholds introduce financial incentives to retire at a certain age. Therefore, we would expect to see disproportionate increases in the retirement probability at these ages, since individuals close to these age thresholds might postpone their retirement until they are eligible for pension benefits.

Formally, an instrumental variable needs to fulfil two assumptions - (i) it should predict the treatment, and (ii) it should not affect the outcome other than through its effect on the treatment. The first assumption is likely to hold, since previous studies have reported that these age thresholds predict retirement (Bonsang et al. 2012; Bound and Waidmann 2007). Moreover, we can assess this assumption visually and empirically (see section 5.1). For the second assumption, we argue that, conditional on a parametric age trend, it appears unlikely that voluntary work provision should change at these age thresholds for reasons not related to retirement. Moreover, these age thresholds vary across countries, and in all three countries pension reforms were introduced that led to an increase in these age thresholds. Thus, it appears highly unlikely that our estimates are confounded by unobserved factors that change at the age thresholds for pension eligibility in all three countries. 
Under these two assumptions, we can estimate the causal effect of retirement on voluntary work using the following model:

$$
\begin{array}{ll}
\text { First stage: } & r_{i t}=1_{\left\{A g e_{i t} \geq S P A\right\}} \pi+A g e_{i t} \gamma_{1}+A g e_{i t}^{2} \gamma_{2}+\text { Wave }_{i t}+v_{i t} \\
\text { Second stage: } & y_{i t}=r_{i t} \tau+A g e_{i t} \beta_{1}+A g e_{i t}^{2} \beta_{2}+\text { Wave }_{i t}+\epsilon_{i t}
\end{array}
$$

Intuitively, in the first stage of the model we regress retirement status of individual $i$ in year $t$ on a binary indicator for observations above the relevant state pension age (for the HRS data, we use two binary indicators for the age thresholds at 62 and 65), $1_{\left\{A g e_{i t} \geq S P A\right\}}$, as well as a quadratic age trend and wave dummies to obtain a predicted value for retirement status, which is independent of any unobserved confounders (these are absorbed in the error term of the model, $v_{i t}$ ). In the second stage of the model, we regress our outcomes indicating the frequency of voluntary work provision $\left(y_{i t}\right)$ on predicted retirement status, the quadratic age trend and wave dummies to obtain an estimate of the causal effect of retirement on voluntary work, $\tau$. We also estimate a second specification, which includes predetermined control variables for education, ethnicity and partnership status. We estimate these models using two-stage least squares (2SLS) with standard errors clustered on the individual-level to account for heteroscedasticity and serial correlation of the error terms.

\subsection{Complier Population}

An important limitation of the IV approach is that it does not provide us with an estimate of the average treatment effect, but rather an estimate of the local average treatment effect (LATE). The LATE refers to the treatment effect for the complier population, i.e., those units whose treatment assignment is determined by the instrument. In our study, these are individuals who do not retire when they are below the age threshold for state pension eligibility, but who do retire once they reach the threshold. In all three countries in focus, the benefits only provide a basic amount of old-age income. To illustrate, the state pension in the UK ranges between $£ 129.20$ and $£ 168.6$ per week. In Ireland it ranges between $€ 237.0$ and $€ 248.3$ per week. For many individuals with higher socioeconomic status, the majority (or even all) of their old-age income will come from occupational and private pensions. Therefore, eligibility thresholds for the state pension will be less relevant for such individuals, and they are likely to be underrepresented in the complier population. Extrapolating the LATE from the complier population to the overall population is not possible without restrictive assumptions. Therefore, we examine effect heterogeneity between subpopulations as well as the composition of the 
complier population to allow us to draw some conclusions on the generalizability of our 2SLS estimates.

We estimate treatment effect heterogeneity by re-estimating the model separately for subgroups defined by predetermined covariates, notably education and partnership status. By estimating separate models rather than including interaction effects, we allow for different age trends between the subgroups. Similarly, we estimate separate models for individuals who reported voluntary work provision in the previous wave and individuals who did not volunteer in the previous wave to examine whether the impact of retirement differs by previous voluntary work provision.

We examine the composition of the complier population, stratified by sex, following an approach outlined by Angrist and Pischke (2009, p. 172). We define subgroups using mutually exclusive binary indicators, i.e. for education ("less than secondary”, "secondary" and "tertiary”), partnership status ("not in a partnership” and “in a partnership”) or self-reported health ("not in good health" and "good health"). Then, we re-estimate the first-stage of the IV estimator for each subgroup. By comparing the estimated coefficient on the instrument for the subgroup to the estimated coefficient on the instrument in the overall sample, we can obtain an estimate of the relative likelihood that a complier belongs to the specified subgroup.

\subsection{Sensitivity Analysis}

Finally, we conduct a number of robustness checks to assess the sensitivity of our findings. First, we explore alternative treatment definitions by (i) defining homemakers as not retired, (ii) including unemployed individuals as retired, (iii) defining permanently sick or disabled individuals as retired. Then, (iv) we limit the age range for included observations from 50-79 to 55-74 to improve the fit of the quadratic age trend in our model and reduce potential bias due to nonlinearities in the true age trend. Following a similar logic, we explore ( $v$ ) cubic and (vi) quartic polynomials for age. Finally, we re-estimate our model including (vii) individual fixed effects to account for the longitudinal structure of the data. While individual fixed effects are not required for causal identification in an IV model, they might reduce variation in the data by controlling for unobserved heterogeneity. 


\section{Results}

\subsection{First stage estimates}

Table 2 shows the estimates from the first-stage of our 2SLS regression model, by study and sex. In all three datasets, the instruments are significant predictors of retirement status. The state pension age seems to be most relevant in the ELSA data, where being above the state pension age increases the retirement probability for both men and women by about 30 percentage points. In Ireland, we observe heterogeneity between men and women. For men, the retirement probability increases at the state pension age by around 36 percentage points, while the increase for women is markedly lower at 22 percentage points. Finally, in the HRS data the retirement probability increases by around 18 percentage points at age 62 for both men and women, and by 12 percentage points for men and 13 percentage points for women at age 65.

$<$ Table 2 about here $>$

\subsection{Effects of Retirement on Voluntary Work}

Table 3 shows the estimates of the causal effect of retirement on voluntary work provision. First, we note that in all three countries, retirement leads to an increase in voluntary work provision for both men and women. In England and Ireland, retirement leads to a stronger increase in voluntary work provided at higher frequencies. The effects for any voluntary work provision are considerably smaller and less precisely estimated than for volunteering carried out "at least monthly" or "at least weekly". In the U.S., retirement leads to an increase in voluntary work provision at all frequencies. However, the increases are larger for " $50+$ hours" and “ $100+$ hours" of voluntary work provision per annum. Interestingly, the size of the effects is broadly similar for men and women, and even across countries, with increases between 10 and 20 percentage points. These correspond to relative increases between 37\% and 124\% per cent (based on the means reported in Table 1). Including additional covariates into the model increases the precision of the estimates but does not alter our conclusions in any meaningful way. The corresponding estimates for Table 3 are shown in Table A.1 in the appendix.

$<$ Table 3 about here $>$ 


\subsection{Effect Heterogeneity}

Table 4 shows differences in the effect of retirement on voluntary work between education groups. For men, we find that the effects are primarily driven by medium- and higheducated individuals in all three countries. For women, the pattern is less clear. In the English data, there are significant increases for medium-educated women and large but insignificant effects for highly educated women. For Ireland, we observe sizable effects for women of all education levels, however, these are never statistically significant. For the U.S., we find statistically significant increases for women of all education levels.

\section{$<$ Table 4 about here $>$}

Table 5 shows differences by partnership status. For England, we observe a clear pattern. Voluntary work provision increases significantly at retirement only for men and women in a partnership. For Ireland, we find significant increases for men regardless of partnership status, while only partnered women exhibit large increases in voluntary work provision. However, these are imprecisely estimated.

For the U.S., we observe significant increases in voluntary work provision only for women who are not in a partnership. The point estimates for women in a partnership are small and statistically insignificant. In contrast, we find significant increases in voluntary work provision only for men in a partnership. However, the point estimates for men who are not in a partnership are relatively large, but imprecisely estimated. This may be partly because the instruments are weaker in this group.

$<$ Table 5 about here $>$

\subsection{Previous Voluntary Work Provision}

We examine the role of previous voluntary work engagement in Table 6. In all three countries, retirement leads to strong and significant increases in voluntary work provision among men who were volunteering in the previous wave. In England, the increase in voluntary work for "at least monthly” and "at least weekly” ranges between 30 and 38 percentage points. The corresponding figures for Ireland range between 18 and 27 percentage points. In the U.S., the largest increase is for " $50+$ hours" with about 40 percentage points; for " $100+$ hours" of voluntary work provision per annum the increase is 27 percentage points. Among women who were volunteering in the previous wave, the effect is significant only in England. The effects 
of retirement on volunteering for individuals who were not volunteering in the previous wave is strong and significant only in the US.

$<$ Table 6 about here $>$

\subsection{Composition of the Complier Population}

Table 7 shows the relative likelihood of individuals to belong to the complier population. Similar to the previous section, we examined partnership status, education as well as self-reported health. In line with expectations, we find that lower educated men and women are overrepresented in the complier population, i.e., the likelihood to be a complier decreases across education categories. This is likely because better educated individuals rely less on the basic state pension for their old-age income, and therefore the eligibility age thresholds are less relevant to these groups. The exception are women in the U.S., where higher educated women are more likely to comply with these age thresholds.

Interestingly, we find that in England and Ireland, individuals in a partnership are less likely to comply with these age thresholds, while in the U.S. the opposite holds. In England and Ireland these differences are more pronounced for women than for men. It seems plausible that joint retirement might play a role, i.e., individuals in a partnership are less likely to comply with the state pension age, since they prefer to retire at the same time as their partner. However, it is not clear why this mechanism would not hold in the U.S. Finally, we see that in England compliers are more likely to be in poor health, while the opposite holds for the U.S. In Ireland, men in poor health are more likely to comply with the state pension age, while the opposite effect is observed for women.

$<$ Table 7 about here $>$

\subsection{Robustness Checks}

Tables A2 and A3 in the appendix show the results from a number of robustness checks conducted to assess the sensitivity of our findings to changes in the retirement definition, the age range of the sample, the functional form of the age trend and inclusion of individual fixed effects. Table A2 shows results for men. Table A3 shows results for women. We note that using different definitions of retirement (i.e., whether homemakers, unemployed and permanently sick or disabled individuals are considered as retired or not) does not affect our conclusions. 
Reducing the age range or modelling age with a cubic or quartic polynomial reduces the precision of our estimates (as expected). For England, the point estimates for women are considerably reduced, while the point estimates for men remain stable. For Ireland, the point estimates for both men and women are reduced, although the decrease is larger for women. For the U.S., the point estimates for both men and women remain relatively stable. Finally, the inclusion of individual fixed effects seems to generally improve precision (and in some cases also increases the point estimates). Thus, our main specification without individual fixed effects can be considered “conservative”. All in all, we conclude that our conclusions are robust to changes in these assumptions.

\section{Discussion}

This paper examines the causal effect of retirement on voluntary work provision in England, Ireland and the U.S. We use an instrumental variable approach to address potential bias due to selection into retirement. We exploit age thresholds in the eligibility criteria for state pension or Social Security benefits as instruments for retirement. We find remarkable consistency in the relationship between retirement and voluntary work in all three countries: retirement leads to an increase in the probability to volunteer by 10-20 percentage points. While we find significant effects for both men and women, the effects are stronger and more precisely estimated for men than for women. These findings support the hypothesis of activity substitution between employment and voluntary work, and are consistent with theoretical explanations based on opportunity costs of time investments or role stability.

We observe some differences across countries when looking at the frequency of voluntary work provision as well as treatment heterogeneity. While in the U.S. the increases in voluntary work provision are relatively homogenous across all frequencies of volunteering, we observe stronger increases in more frequent (i.e., monthly or weekly) volunteering in England and Ireland. Moreover, the patterns for partnered and unpartnered individuals differ across countries.

This is one of the first studies to examine the causal relationship between voluntary work provision and labour market participation (Laferrère 2016). Our findings provide further evidence that older workers face important trade-offs in their time investment decisions (Eibich and Siedler 2020; Fischer and Müller 2019). Retirement relaxes these constraints and allows retirees to engage in other activities that are both beneficial to the individual (e.g., health investments) and to the wider society, such as provision of voluntary work. Thus, retirement 
can be an important part of an "active ageing” process by allowing older individuals to shift their priorities from employment to other commitments.

Yet, labour market policies in many developing countries aim to increase labour market participation at older ages, e.g., by raising the retirement age. Our results imply that such policies can have unintended consequences for the provision of voluntary work, at least in the short-term, as older workers will spend more of their time in employment rather than volunteering. Moreover, depending on the health effects of prolonged working lives, postponing retirement might further reduce voluntary work provision if retirees at older ages have fewer capacities to volunteer due to health limitations.

The remarkable similarity of our main finding across all three countries suggests that our findings should extend to other contexts as well, especially since the relevant mechanisms are not unique to the three countries included in this study. Yet, it is important to recognise that all three countries share certain institutional and economic characteristics, which might affect the applicability of our findings to other settings. The UK, Ireland and the U.S. are often grouped under the so-called liberal regime type (Bambra 2007) as they have similar welfare systems. In the three countries, the state pension benefits only act as a basic source of old-age income, and many individuals will have additional and more important sources of pension income. This means that in these countries the group of individuals retiring at the state pension age might be very different than in countries with a more generous pension system.

Our IV approach only allows us to draw conclusions on the population of compliers, i.e., those individuals retiring at the state pension age. However, our analysis of treatment effect heterogeneity suggests that our causal estimates are primarily driven by, e.g., better educated individuals, which are under-represented in the complier population. On the one hand, this opens up the possibility that those better educated individuals retiring at the state pension age differ considerably from the majority of people with secondary or tertiary education. On the other hand, higher educated individuals retiring before the state pension age or retiring at older ages nevertheless face the same time trade-off as those that retire at the state pension age, and therefore it seems plausible that the relationship between retirement and voluntary work provision is similar in both groups.

Another limitation of our study is the lack of information on the type of voluntary work. We restricted our analysis to relatively simple measures of the frequency of formal voluntary work provision to facilitate comparisons across countries. The consequences of voluntary work for the individual volunteer as well as the overall benefits to society are likely to differ between different types of activities. It would therefore be highly interesting to differentiate between 
varying types of activities, including formal and informal voluntary work. Moreover, given the sustained interest in volunteering as part of an "active ageing" strategy (e.g., Bechetti et al., 2015; Chiao, 2019; Huang, 2019), it should be a priority for future research to consider voluntary work as a mediator for the health effects of retirement (Eibich 2015; Insler 2014).

\section{Conclusions}

This study examines the causal effect of retirement on voluntary work provision. We draw on data from longitudinal ageing studies in England, Ireland and the U.S. for the period 2009-2017. We use instrumental variable estimation to account for selection into retirement using age thresholds for state pensions and Social Security benefits as instruments. We find that retirement increases voluntary work provision in all three countries, thus supporting the hypothesis of activity substitution between paid work and voluntary work. 


\section{References}

Angrist, J., \& Pischke, J.-S. (2009). Mostly harmless econometrics. Princeton and Oxford: Princeton University Press.

Atchley, R. C. (1989). A Continuity Theory of Normal Aging. The Gerontologist, 29(2), 183-190. https://doi.org/10.1093/geront/29.2.183

Bambra, C. (2007). Going beyond The three worlds of welfare capitalism: regime theory and public health research. Journal of Epidemiology \& Community Health, 61(12), 1098-1102. https://doi.org/10.1136/jech.2007.064295

Bechetti, L., Conzo, P., \& Di Febbraro, M. (2015). Voluntary Work, Health and Subjective Wellbeing: a Resource for Active Ageing (Department of Economics and Statistics Cognetti de Martiis. Working Paper No. 201511). University of Turin. https://ideas.repec.org/p/uto/dipeco/201511.html. Accessed 23 February 2016

Becker, G. S. (1981). A Treatise on the Family. Cambridge, Massachusetts: Harvard University Press.

Bonsang, E., Adam, S., \& Perelman, S. (2010). Does Retirement Affect Cognitive Functioning? Maastricht University, Research Centre for Education and the Labour Market (ROA). https://ideas.repec.org/p/unm/umaror/2010001.html

Bonsang, E., Adam, S., \& Perelman, S. (2012). Does retirement affect cognitive functioning? Journal of Health Economics, 31, 490-501. https://doi.org/10.1016/j.jhealeco.2012.03.005

Bonsang, E., \& van Soest, A. (2020). Time Devoted to Home Production and Retirement in Couples: A Panel Data Analysis. Labour Economics, 101810. https://doi.org/10.1016/j.labeco.2020.101810

Bound, J., \& Waidmann, T. (2007). Estimating the Health Effects of Retirement. University of Michigan Retirement Research Center Working Paper, 168.

Bureau of Labor Statistics. (2016). Volunteering in the United States News Release (No. USDL-16-0363). https://www.bls.gov/news.release/archives/volun_02252016.htm. Accessed 2 April 2020

Caro, F. G., \& Bass, S. A. (1997). Receptivity to Volunteering in the Immediate Postretirement Period. Journal of Applied Gerontology, 16(4), 427-441. https://doi.org/10.1177/073346489701600403

Central Statistics Office. (2015). QNHS Volunteering and Wellbeing Q3 2013 (CSO Statistical Release). https://www.cso.ie/en/releasesandpublications/er/q-vwb/qnhsvolunteeringandwellbeingq32013/.

Accessed 2 April 2020 
Chambré, S. M. (1984). Is Volunteering A Substitute for Role Loss in Old Age? An Empirical Test of Activity Theory1. The Gerontologist, 24(3), 292-298. https://doi.org/10.1093/geront/24.3.292

Chiao, C. (2019). Beyond health care: Volunteer work, social participation, and late-life general cognitive status in Taiwan. Contextualizing Productive Aging in Asia, 229, 154-160. https://doi.org/10.1016/j.socscimed.2018.06.001

Di Gessa, G., \& Grundy, E. (2016). The Dynamics of Paid and Unpaid Activities Among People Aged 50-69 in Denmark, France, Italy, and England. Research on Aging, 39(9), 1013-1038. https://doi.org/10.1177/0164027516654521

Dudel, C., López Gómez, M. A., Benavides, F. G., \& Myrskylä, M. (2018). The Length of Working Life in Spain: Levels, Recent Trends, and the Impact of the Financial Crisis. European Journal of Population, 34(5), 769-791. https://doi.org/10.1007/s10680-017-9458-9

Dudel, C., \& Myrskylä, M. (2017). Working Life Expectancy at Age 50 in the United States and the Impact of the Great Recession. Demography, 54(6), 2101-2123. https://doi.org/10.1007/s13524-017-0619-6

Eibich, P. (2015). Understanding the effect of retirement on health: Mechanisms and Heterogeneity. Journal of Health Economics, 43, 1-12. https://doi.org/10.1016/j.jhealeco.2015.05.001

Eibich, P., \& Siedler, T. (2020). Retirement, intergenerational time transfers, and fertility. European Economic Review, 124, 103392. https://doi.org/10.1016/j.euroecorev.2020.103392

Erlinghagen, M. (2010). Volunteering After Retirement. European Societies, 12(5), 603-625. https://doi.org/10.1080/14616691003716902

Fischer, B., \& Müller, K.-U. (2019). Time to care? The effects of retirement on informal care provision (DIW Discussion Papers No. 1809). Berlin: Deutsches Institut für Wirtschaftsforschung (DIW). http://hdl.handle.net/10419/201389

Galama, T., Kapteyn, A., Fonseca, R., \& Michaud, P.-C. (2013). A health production model with endogenous retirement. Health Economics, 22, 883-902. https://doi.org/10.1002/hec.2865

Gilfillan, G., \& Andrews, L. (2010). Labour Force Participation of Women Over 45. Productivity Commission, Government of Australia. https://ideas.repec.org/p/ris/prodsw/2020_011.html

Grossman, M. (1972). On the Concept of Health Capital and the Demand for Health. Journal of Political Economy, 80(2), 223-255.

Heller-Sahlgren, G. (2017). Retirement blues. Journal of Health Economics, 54(Supplement C), 66-78. https://doi.org/10.1016/j.jhealeco.2017.03.007 
Huang, L.-H. (2019). Well-being and volunteering: Evidence from aging societies in Asia. Contextualizing Productive Aging in Asia, 229, 172-180. https://doi.org/10.1016/j.socscimed.2018.09.004

Insler, M. (2014). The Health Consequences of Retirement. Journal of Human Resources, 49(1), $195-233$.

Kearney, P. M., Cronin, H., O’Regan, C., Kamiya, Y., Savva, G. M., Whelan, B., \& Kenny, R. (2011). Cohort Profile: The Irish Longitudinal Study on Ageing. International Journal of Epidemiology, 40(4), 877884. https://doi.org/10.1093/ije/dyr116

Komp, K., van Tilburg, T., \& van Groenou, M. B. (2012). Age, Retirement, and Health as Factors in Volunteering in Later Life. Nonprofit and Voluntary Sector Quarterly, 41(2), 280-299. https://doi.org/10.1177/0899764011402697

Laferrère, A. (2016). Retired, but still active: Is retirement a springboard for new activities? Retraite et société, 73(1), 89-118.

Lancee, B., \& Radl, J. (2014). Volunteering over the Life Course. Social Forces, 93(2), 833-862. https://doi.org/10.1093/sf/sou090

Luo, Y., Pan, X., \& Zhang, Z. (2019). Productive activities and cognitive decline among older adults in China: Evidence from the China Health and Retirement Longitudinal Study. Contextualizing Productive Aging in Asia, 229, 96-105. https://doi.org/10.1016/j.socscimed.2018.09.052

McGarry, K. (2004). Health and Retirement: Do Changes in Health Affect Retirement Expectations? Journal of Human Resources, 39(3), 624-648.

Mosca, I., \& Wright, R. E. (2017). Working, Volunteering and Mental Health in the Later Years. Institute for the Study of Labor (IZA). https://ideas.repec.org/p/iza/izadps/dp11100.html

Mutchler, J. E., Burr, J. A., \& Caro, F. G. (2003). From Paid Worker to Volunteer: Leaving the Paid Workforce and Volunteering in Later Life*. Social Forces, 81(4), 1267-1293. https://doi.org/10.1353/sof.2003.0067

Nazroo, J. (2015). Volunteering, providing informal care and paid employment in later life: role occupancy and implications for well-being. https://www.gov.uk/government/uploads/system/uploads/attachment_data/file/434398/gs-15-5-futureageing-volunteering-er20.pdf. Accessed 23 February 2016

Nishimura, Y., Oikawa, M., \& Motegi, H. (2018). What Explains the Difference in the Effect of Retirement on Health? Evidence from Global Aging Data. Journal of Economic Surveys, 32(3), $792-847$. https://doi.org/10.1111/joes.12215 
Office for National Statistics. (2017). Changes in the value and division of unpaid volunteering in the UK: 2000

to

2015.

https://www.ons.gov.uk/economy/nationalaccounts/satelliteaccounts/articles/changesinthevalueanddivi sionofunpaidcareworkintheuk/2015. Accessed 2 April 2020

Okun, M. A., Barr, A., \& Herzog, A. R. (1998). Motivation to volunteer by older adults: A test of competing measurement models. Psychology and Aging, 13(4), 608-621. https://doi.org/10.1037/08827974.13.4.608

Schmitz, H., \& Westphal, M. (2015). Short- and medium-term effects of informal care provision on female caregivers' health. Journal of Health Economics, 42, 174-185. https://doi.org/10.1016/j.jhealeco.2015.03.002

Smith, S. (2010). Social connectedness and retirement. CMPO Working Paper Series, 10/255.

Sonnega, A., Faul, J. D., Ofstedal, M. B., Langa, K. M., Phillips, J. W., \& Weir, D. R. (2014). Cohort Profile: the Health and Retirement Study (HRS). International Journal of Epidemiology, 43(2), 576-585. https://doi.org/10.1093/ije/dyu067

Stancanelli, E., \& van Soest, A. (2012). Retirement and Home Production: A Regression Discontinuity Approach. American Economic Review, 102(3), 600-605. https://doi.org/10.1257/aer.102.3.600

Stancanelli, E., \& van Soest, A. (2016). Partners' leisure time truly together upon retirement. IZA Journal of Labor Policy, 5(1), 12. https://doi.org/10.1186/s40173-016-0068-7

Tang, F. (2015). Retirement Patterns and Their Relationship to Volunteering. Nonprofit and Voluntary Sector Quarterly, 45(5), 910-930. https://doi.org/10.1177/0899764015602128

Taylor, R., Conway, L., Calderwood, L., Lessof, C., Cheshire, H., Cox, K., \& Scholes, S. (2007). Health, wealth and lifestyles of the older population in England: The 2002 English Longitudinal Study of Ageing (Technical Report). National Centre for Social Research. https://www.ifs.org.uk/elsa/report03/w1_tech.pdf. Accessed 2 November 2020

Wilson, J., \& Musick, M. A. (1997). Work and Volunteering: The Long Arm of the Job. Social Forces, 76(1), 251-272. https://doi.org/10.2307/2580325 
Tables and Figures

Table 1: Summary Statistics

\begin{tabular}{|c|c|c|c|c|c|c|}
\hline & \multicolumn{2}{|c|}{ ELSA } & \multicolumn{2}{|c|}{ TILDA } & \multicolumn{2}{|c|}{ HRS } \\
\hline & Mean & S.D. & Mean & S.D. & Mean & S.D. \\
\hline & \multicolumn{6}{|c|}{ A. Outcomes: Volunteering Frequency } \\
\hline Any & 0.384 & 0.486 & 0.587 & 0.492 & 0.373 & 0.484 \\
\hline At least monthly & 0.295 & 0.456 & 0.320 & 0.467 & - & - \\
\hline At least weekly & 0.179 & 0.383 & 0.182 & 0.386 & - & - \\
\hline $50+$ hours per annum & - & - & - & - & 0.234 & 0.424 \\
\hline \multirow[t]{2}{*}{$100+$ hours per annum } & - & - & - & - & 0.148 & 0.355 \\
\hline & \multicolumn{4}{|c|}{ B. Covariates } & & \\
\hline Retired & 0.593 & 0.491 & 0.525 & 0.499 & 0.562 & 0.496 \\
\hline Above state pension age (SPA) & 0.586 & 0.493 & 0.418 & 0.493 & 0.423 & 0.494 \\
\hline Age & 64.968 & 7.317 & 63.552 & 7.567 & 64.558 & 8.276 \\
\hline Female & 0.542 & 0.498 & 0.538 & 0.499 & 0.568 & 0.495 \\
\hline Less than secondary education & 0.304 & 0.460 & 0.220 & 0.414 & 0.162 & 0.369 \\
\hline Secondary education & 0.508 & 0.500 & 0.609 & 0.488 & 0.600 & 0.490 \\
\hline Tertiary education & 0.188 & 0.391 & 0.171 & 0.376 & 0.237 & 0.425 \\
\hline In a partnership & 0.763 & 0.425 & 0.744 & 0.437 & 0.656 & 0.475 \\
\hline Non-Hispanic white ethnicity & 0.961 & 0.195 & - & - & 0.637 & 0.481 \\
\hline $\mathrm{N}$ & \multicolumn{2}{|c|}{25,578} & \multicolumn{2}{|c|}{20,150} & \multicolumn{2}{|c|}{60,882} \\
\hline
\end{tabular}


Table 2: Pension Eligibility and Retirement

\begin{tabular}{|c|c|c|c|}
\hline & ELSA & TILDA & HRS \\
\hline & \multicolumn{3}{|c|}{ Dependent Variable: Retired } \\
\hline Instrument & \multicolumn{3}{|c|}{ A. Men } \\
\hline \multirow{2}{*}{ Instrument $1^{\mathrm{a}}$} & $0.320^{* * *}$ & $0.364^{* * *}$ & $0.176^{* * *}$ \\
\hline & $(0.016)$ & $(0.020)$ & $(0.013)$ \\
\hline \multirow[t]{2}{*}{ Instrument $2^{\mathrm{b}}$} & - & - & $0.118^{* * *}$ \\
\hline & - & - & $(0.013)$ \\
\hline Wald F & 384.1 & 340.1 & 113.6 \\
\hline \multirow[t]{2}{*}{$\mathrm{N}$} & 11,718 & 9,318 & 26,275 \\
\hline & \multicolumn{3}{|c|}{ B. Women } \\
\hline \multirow[t]{2}{*}{ Instrument $1^{\mathrm{a}}$} & $0.294 * * *$ & $0.220^{* * *}$ & $0.177^{* * *}$ \\
\hline & $(0.020)$ & $(0.018)$ & $(0.011)$ \\
\hline \multirow[t]{2}{*}{ Instrument $2^{\mathrm{b}}$} & - & - & $0.131^{* * *}$ \\
\hline & - & - & $(0.011)$ \\
\hline Wald F & 225 & 150.6 & 222.3 \\
\hline $\mathrm{N}$ & 13,860 & 10,832 & 34,607 \\
\hline \multicolumn{4}{|c|}{$\begin{array}{l}\text { a Instrument } 1 \text { is a binary indicator defined as "above the state pension age" in ELSA and TILDA, and "above } 62 \text { " } \\
\text { HRS. } \\
\text { b Instrument } 2 \text { is a binary indicator defined as "above the normal retirement age" in HRS. } \\
\text { Source: ELSA Waves 5-8, TILDA Waves } 1-4 \text {, HRS Waves } 10-13 \text {. Estimates come from a linear regression mod } \\
\text { controlling for quadratic age and survey wave. Clustered standard errors on the individual-level in parentheses. "Wal } \\
\text { F" refers to the Kleibergen-Paap F-statistic on the relevance of the instruments. Significance: } \dagger \mathrm{p}<0.1 \text {, * }<<0.05 \text {, * } \\
\mathrm{p}<0.01 \text {, *** } \mathrm{p}<0.001 \text {. }\end{array}$} \\
\hline
\end{tabular}


Table 3: The effect of retirement on voluntary work

ELSA

Any At least monthly At least weekly

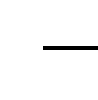

HRS

Any At least monthly At least weekly Any $\quad 50+$ hours $\quad 100+$ hours

\begin{tabular}{|c|c|c|c|c|c|c|c|c|c|}
\hline \multicolumn{10}{|c|}{ A. Men } \\
\hline \multirow[t]{2}{*}{ Retired } & 0.090 & $0.109 *$ & $0.145^{* * * *}$ & 0.0497 & $0.115^{*}$ & $0.165^{* * *}$ & $0.167 * *$ & $0.184^{* *}$ & $0.183^{* * *}$ \\
\hline & $(0.055)$ & $(0.051)$ & $(0.044)$ & $(0.061)$ & $(0.058)$ & $(0.049)$ & $(0.065)$ & $(0.056)$ & $(0.047)$ \\
\hline Wald F & 384.1 & 384.1 & 384.1 & 340.1 & 340.1 & 340.1 & 249.1 & 249.1 & 249.1 \\
\hline $\mathrm{N}$ & 11,718 & 11,718 & 11,718 & 9,318 & 9,318 & 9,318 & 26,275 & 26,275 & 26,275 \\
\hline \multicolumn{10}{|c|}{ B. Women } \\
\hline \multirow[t]{2}{*}{ Retired } & $0.162 *$ & $0.222 * * *$ & $0.167 * *$ & 0.0497 & $0.179^{*}$ & 0.0889 & $0.163^{* *}$ & $0.196 * * *$ & $0.128 * *$ \\
\hline & $(0.071)$ & $(0.066)$ & $(0.054)$ & $(0.095)$ & $(0.091)$ & $(0.077)$ & $(0.055)$ & $(0.049)$ & $(0.040)$ \\
\hline Wald F & 225.0 & 225.0 & 225.0 & 150.6 & 150.6 & 150.6 & 365.8 & 365.8 & 365.8 \\
\hline $\mathrm{N}$ & 13,860 & 13,860 & 13,860 & 10,832 & 10,832 & 10,832 & 34,607 & 34,607 & 34,607 \\
\hline
\end{tabular}

Source: ELSA Waves 5-8, TILDA Waves 1-4, HRS Waves 10-13. Estimates come from a 2SLS regression model controlling for quadratic age and survey wave. Clustered standard errors on the individual-level in parentheses. Significance: $\dagger \mathrm{p}<0.1,{ }^{*} \mathrm{p}<0.05,{ }^{* *} \mathrm{p}<0.01,{ }^{* * *} \mathrm{p}<0.001$. 


\section{Table 4: The effect of retirement on voluntary work by educational attainment}

ELSA

TILDA

Any At least monthly At least
Any At least monthly At least weekly

\section{HRS}

Any $\quad 50+$ hours $\quad 100+$ hours

\begin{tabular}{|c|c|c|c|c|c|c|c|c|c|}
\hline \multicolumn{10}{|c|}{ A. Less than Secondary Education, Men } \\
\hline Retired & 0.088 & $0.124 \dagger$ & 0.077 & 0.0393 & 0.0381 & 0.0397 & -0.068 & 0.045 & 0.0003 \\
\hline & $(0.070)$ & $(0.065)$ & $(0.057)$ & $(0.085)$ & $(0.072)$ & $(0.060)$ & $(0.087)$ & $(0.069)$ & $(0.05)$ \\
\hline \multicolumn{10}{|c|}{ B. Secondary Education, Men } \\
\hline \multirow[t]{2}{*}{ Retired } & $0.145^{*}$ & 0.089 & 0.071 & 0.0838 & 0.121 & $0.175^{*}$ & $0.151 \dagger$ & $0.166^{*}$ & $0.163^{* *}$ \\
\hline & $(0.074)$ & $(0.067)$ & $(0.056)$ & $(0.090)$ & $(0.087)$ & $(0.073)$ & $(0.08)$ & $(0.066)$ & $(0.054)$ \\
\hline \multicolumn{10}{|c|}{ C. Tertiary Education, Men } \\
\hline \multirow[t]{2}{*}{ Retired } & 0.030 & 0.254 & $0.609^{* * *}$ & 0.231 & 0.358 & $0.422^{*}$ & 0.263 & 0.196 & $0.279 \dagger$ \\
\hline & $(0.180)$ & $(0.183)$ & $(0.184)$ & $(0.20)$ & $(0.22)$ & $(0.20)$ & $(0.174)$ & $(0.167)$ & $(0.151)$ \\
\hline \multicolumn{10}{|c|}{ D. Less than Secondary Education, Women } \\
\hline \multirow[t]{2}{*}{ Retired } & -0.048 & 0.041 & 0.028 & 0.135 & 0.228 & 0.225 & $0.245 \dagger$ & $0.205^{*}$ & 0.077 \\
\hline & $(0.101)$ & $(0.086)$ & $(0.067)$ & $(0.19)$ & $(0.16)$ & $(0.14)$ & $(0.131)$ & $(0.096)$ & $(0.065)$ \\
\hline \multicolumn{10}{|c|}{ E. Secondary Education, Women } \\
\hline \multirow[t]{2}{*}{ Retired } & $0.292 * *$ & $0.314^{* * *}$ & $0.276^{* * *}$ & 0.0633 & 0.112 & -0.032 & $0.118 \dagger$ & $0.164 * *$ & $0.106^{*}$ \\
\hline & $(0.096)$ & $(0.089)$ & $(0.072)$ & $(0.11)$ & $(0.11)$ & $(0.095)$ & $(0.067)$ & $(0.057)$ & $(0.047)$ \\
\hline \multicolumn{10}{|c|}{ F. Tertiary Education, Women } \\
\hline \multirow[t]{2}{*}{ Retired } & 0.234 & $0.415 \dagger$ & 0.120 & 0.091 & 0.470 & $0.534 \dagger$ & $0.304^{* *}$ & $0.340^{* *}$ & $0.260 * *$ \\
\hline & $(0.230)$ & $(0.240)$ & $(0.211)$ & $(0.28)$ & $(0.34)$ & $(0.32)$ & (0.111) & $(0.112)$ & (0.099) \\
\hline
\end{tabular}


Table 5: The effect of retirement on voluntary work by partnership status

ELSA

\begin{tabular}{|c|c|c|c|c|c|c|c|c|c|}
\hline & \multicolumn{3}{|c|}{ ELSA } & \multicolumn{3}{|c|}{ TILDA } & \multicolumn{3}{|c|}{ HRS } \\
\hline & Any & $\begin{array}{l}\text { At least } \\
\text { monthly }\end{array}$ & $\begin{array}{l}\text { At least } \\
\text { weekly }\end{array}$ & Any & $\begin{array}{l}\text { At least } \\
\text { monthly }\end{array}$ & $\begin{array}{c}\text { At least } \\
\text { weekly }\end{array}$ & Any & $50+$ hours & $100+$ hours \\
\hline \multicolumn{10}{|c|}{ A. Not in a Partnership, Men } \\
\hline \multirow[t]{2}{*}{ Retired } & -0.113 & -0.115 & -0.083 & $0.215^{* * * *}$ & $0.221^{*}$ & $0.211^{*}$ & -0.088 & 0.068 & 0.062 \\
\hline & $(0.119)$ & $(0.108)$ & $(0.093)$ & $(0.11)$ & $(0.10)$ & $(0.086)$ & $(0.129)$ & $(0.109)$ & $(0.089)$ \\
\hline \multicolumn{10}{|c|}{ B. In a Partnership, Men } \\
\hline \multirow[t]{2}{*}{ Retired } & $0.137 *$ & $0.161 * *$ & $0.194 * * *$ & -0.0106 & 0.0773 & $0.150^{*}$ & $0.177 *$ & $0.176^{* *}$ & $0.190 * * *$ \\
\hline & $(0.061)$ & $(0.057)$ & $(0.049)$ & $(0.073)$ & $(0.069)$ & $(0.059)$ & $(0.07)$ & $(0.062)$ & $(0.052)$ \\
\hline \multicolumn{10}{|c|}{ C. Not in a Partnership, Women } \\
\hline \multirow[t]{2}{*}{ Retired } & -0.028 & 0.031 & 0.078 & -0.0823 & 0.0656 & 0.0218 & 0.156 & $0.253 * *$ & $0.182 * *$ \\
\hline & $(0.110)$ & $(0.098)$ & $(0.076)$ & $(0.12)$ & $(0.11)$ & $(0.095)$ & $(0.097)$ & $(0.085)$ & $(0.068)$ \\
\hline \multicolumn{10}{|c|}{ D. In a Partnership, Women } \\
\hline \multirow[t]{2}{*}{ Retired } & $0.232 * *$ & $0.294^{* * *}$ & $0.205^{* *}$ & 0.1000 & 0.223 & 0.129 & 0.11 & $0.144 *$ & $0.089 \dagger$ \\
\hline & $(0.090)$ & $(0.085)$ & $(0.070)$ & $(0.14)$ & $(0.14)$ & $(0.12)$ & $(0.067)$ & $(0.06)$ & $(0.05)$ \\
\hline
\end{tabular}

Source: ELSA Waves 5-8, TILDA Waves 1-4, HRS Waves 10-13. Estimates come from a 2SLS regression model controlling for quadratic age and survey wave. ELSA and TILDA results use state pension ages as instruments. HRS results use age thresholds at 62 and 65 as instruments. Clustered standard errors on the individual-level in parentheses. Significance: $\dagger p<0.1,{ }^{*} p<0.05,{ }^{* *} p<0.01,{ }^{* * *} p<0.001$. 
Table 6: The effect of retirement on voluntary work by previous voluntary work provision

\begin{tabular}{|c|c|c|c|c|c|c|c|c|c|}
\hline & \multicolumn{3}{|c|}{ ELSA } & \multicolumn{3}{|c|}{ TILDA } & \multicolumn{3}{|c|}{ HRS } \\
\hline & Any & $\begin{array}{l}\text { At least } \\
\text { monthly }\end{array}$ & $\begin{array}{l}\text { At least } \\
\text { weekly }\end{array}$ & Any & $\begin{array}{l}\text { At least } \\
\text { monthly }\end{array}$ & $\begin{array}{c}\text { At least } \\
\text { weekly }\end{array}$ & Any & $50+$ hours & $100+$ hours \\
\hline \multicolumn{10}{|c|}{ A. Did not volunteer in the previous wave, Men } \\
\hline \multirow[t]{2}{*}{ Retired } & 0.057 & 0.007 & 0.035 & 0.137 & 0.0121 & 0.0533 & 0.068 & 0.068 & $0.149 * * *$ \\
\hline & $(0.056)$ & $(0.045)$ & $(0.031)$ & $(0.10)$ & $(0.063)$ & $(0.049)$ & $(0.074)$ & $(0.055)$ & $(0.044)$ \\
\hline \multicolumn{10}{|c|}{ B. Volunteered in the previous wave, Men } \\
\hline \multirow[t]{2}{*}{ Retired } & 0.173 & $0.306 *$ & $0.382 *$ & -0.0511 & 0.185 & $0.266^{*}$ & $0.238 \dagger$ & $0.393 *$ & 0.260 \\
\hline & $(0.134)$ & $(0.154)$ & $(0.155)$ & $(0.077)$ & $(0.11)$ & $(0.11)$ & $(0.130)$ & $(0.190)$ & $(0.246)$ \\
\hline \multicolumn{10}{|c|}{ C. Did not volunteer in the previous wave, Women } \\
\hline \multirow[t]{2}{*}{ Retired } & 0.090 & 0.058 & 0.038 & -0.075 & 0.009 & 0.024 & 0.011 & $0.120 *$ & $0.081 *$ \\
\hline & $(0.067)$ & $(0.053)$ & $(0.040)$ & $(0.13)$ & $(0.087)$ & $(0.073)$ & $(0.075)$ & $(0.052)$ & $(0.041)$ \\
\hline \multicolumn{10}{|c|}{ D. Volunteered in the previous wave, Women } \\
\hline \multirow[t]{2}{*}{ Retired } & $0.188 \dagger$ & $0.366^{* *}$ & $0.378^{* *}$ & -0.133 & 0.030 & -0.009 & 0.130 & 0.101 & -0.063 \\
\hline & $(0.110)$ & (0.135) & (0.136) & $(0.11)$ & $(0.16)$ & $(0.15)$ & $(0.080)$ & $(0.110)$ & $(0.133)$ \\
\hline
\end{tabular}

Source: ELSA Waves 5-8, TILDA Waves 1-4, HRS Waves 10-13. Estimates come from a 2SLS regression model controlling for quadratic age and survey wave. ELSA and TILDA results use state pension ages as instruments. HRS results use age thresholds at 62 and 65 as instruments. Clustered standard errors on the individual-level in parentheses. Significance: $\dagger p<0.1,{ }^{*} p<0.05,{ }^{* *} p<0.01$, ${ }^{* * *} p<0.001$. 


\section{Table 7: Complier Characteristics}

\begin{tabular}{|c|c|c|c|c|c|c|c|c|}
\hline & \multicolumn{2}{|l|}{ ELSA } & \multicolumn{2}{|c|}{ TILDA } & \multicolumn{4}{|l|}{ HRS } \\
\hline & \multirow[b]{2}{*}{ Men } & \multirow[b]{2}{*}{ Women } & \multirow[b]{2}{*}{ Men } & \multirow[b]{2}{*}{ Women } & \multicolumn{2}{|l|}{62} & \multicolumn{2}{|l|}{65} \\
\hline & & & & & Men & Women & Men & Women \\
\hline Not in a partnership & 1.125 & 1.320 & 1.228 & 1.454 & 1.005 & 0.809 & 0.667 & 0.894 \\
\hline In a partnership & 0.978 & 0.905 & 0.912 & 0.775 & 1.031 & 1.095 & 1.111 & 1.038 \\
\hline Less than secondary education & 1.288 & 1.190 & 1.277 & 1.022 & 1.425 & 0.894 & 1.500 & 0.756 \\
\hline Secondary education & 1.072 & 0.993 & 0.915 & 1.022 & 1.073 & 1.050 & 0.951 & 0.938 \\
\hline Tertiary education & 0.609 & 0.741 & 0.644 & 0.731 & 0.694 & 0.899 & 0.826 & 1.256 \\
\hline Poor health & 1.331 & 1.190 & 1.149 & 0.705 & 1.073 & 1.075 & 1.104 & 1.113 \\
\hline Good health & 0.875 & 0.942 & 0.928 & 1.022 & 0.829 & 0.874 & 0.785 & 0.763 \\
\hline
\end{tabular}

Source: ELSA Waves 5-8, TILDA Waves 1-4, HRS Waves 10-13. The numbers show the relative likelihood that an individual with a given characteristic is part of the complier population in the working sample. 
Figure 1: Self-reported labour market status
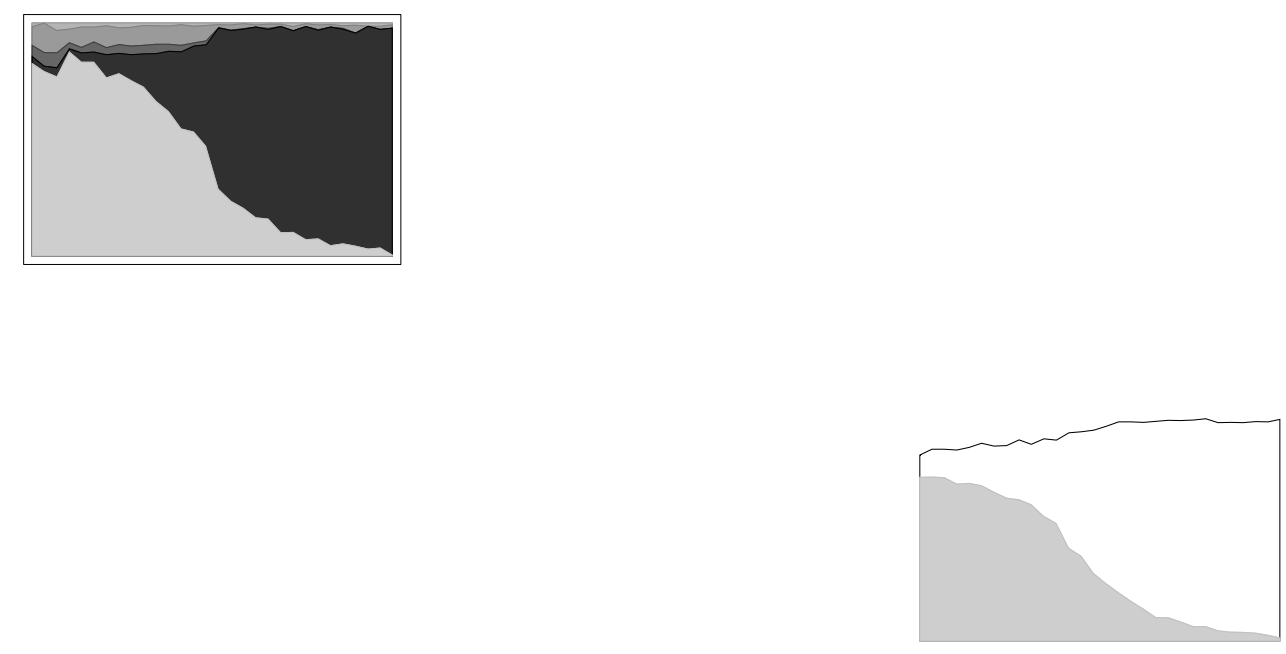

Source: ELSA Waves 5-8, TILDA Waves 1-4, HRS Waves 10-13.

For comparability purposes, individuals coded as "not in the labour force" in HRS are considered as homemakers. 


\section{Figure 2: Volunteering by Age, Men}
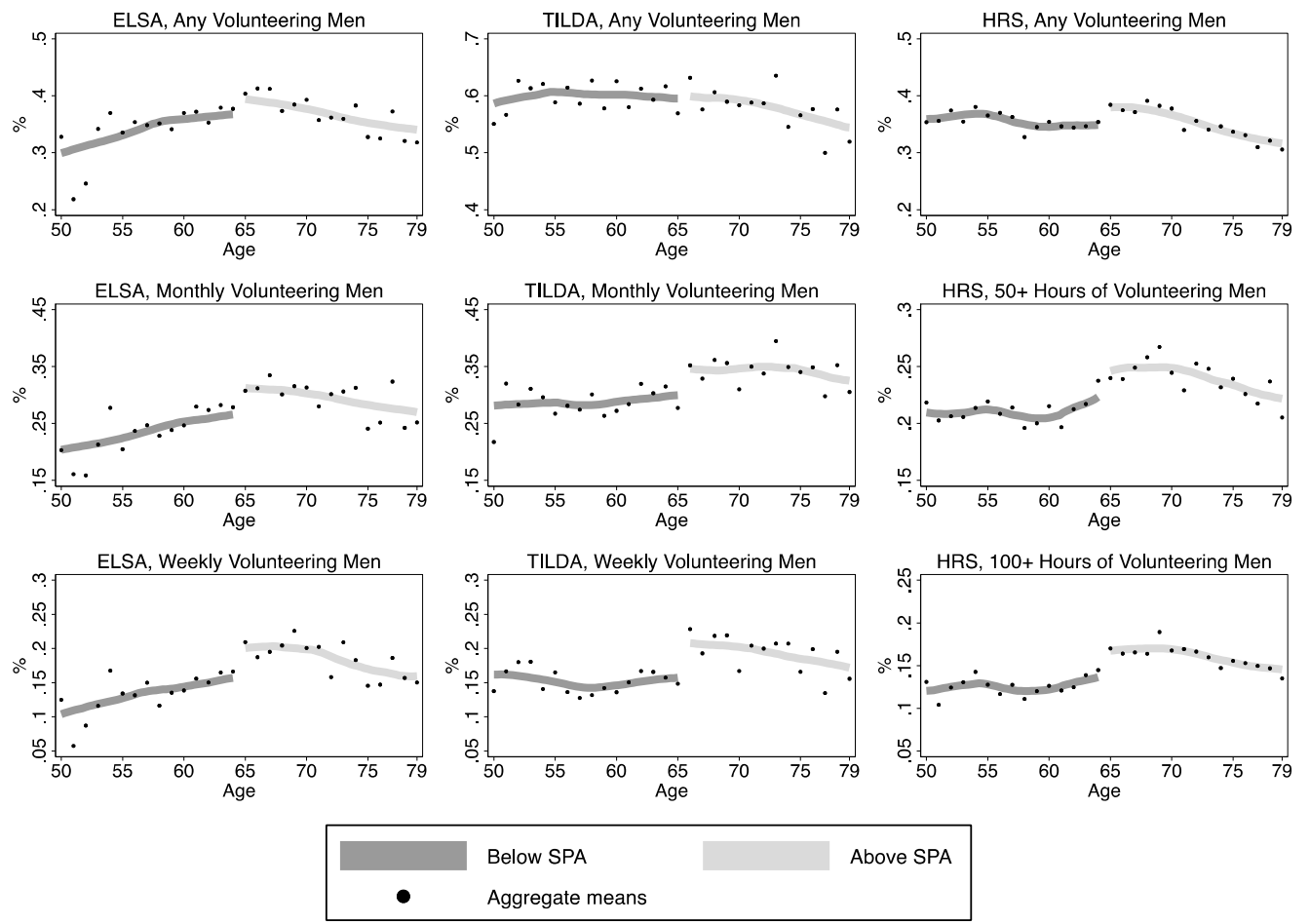

Source: ELSA Waves 5-8, TILDA Waves 1-4, HRS Waves 10-13

In Figure 2, state pension age (SPA) is defined as age 65 for England and the US and age 66 for Ireland. The grey lines show nonparametric fits based on local mean smoothing. 


\section{Figure 3: Volunteering by Age, Women}
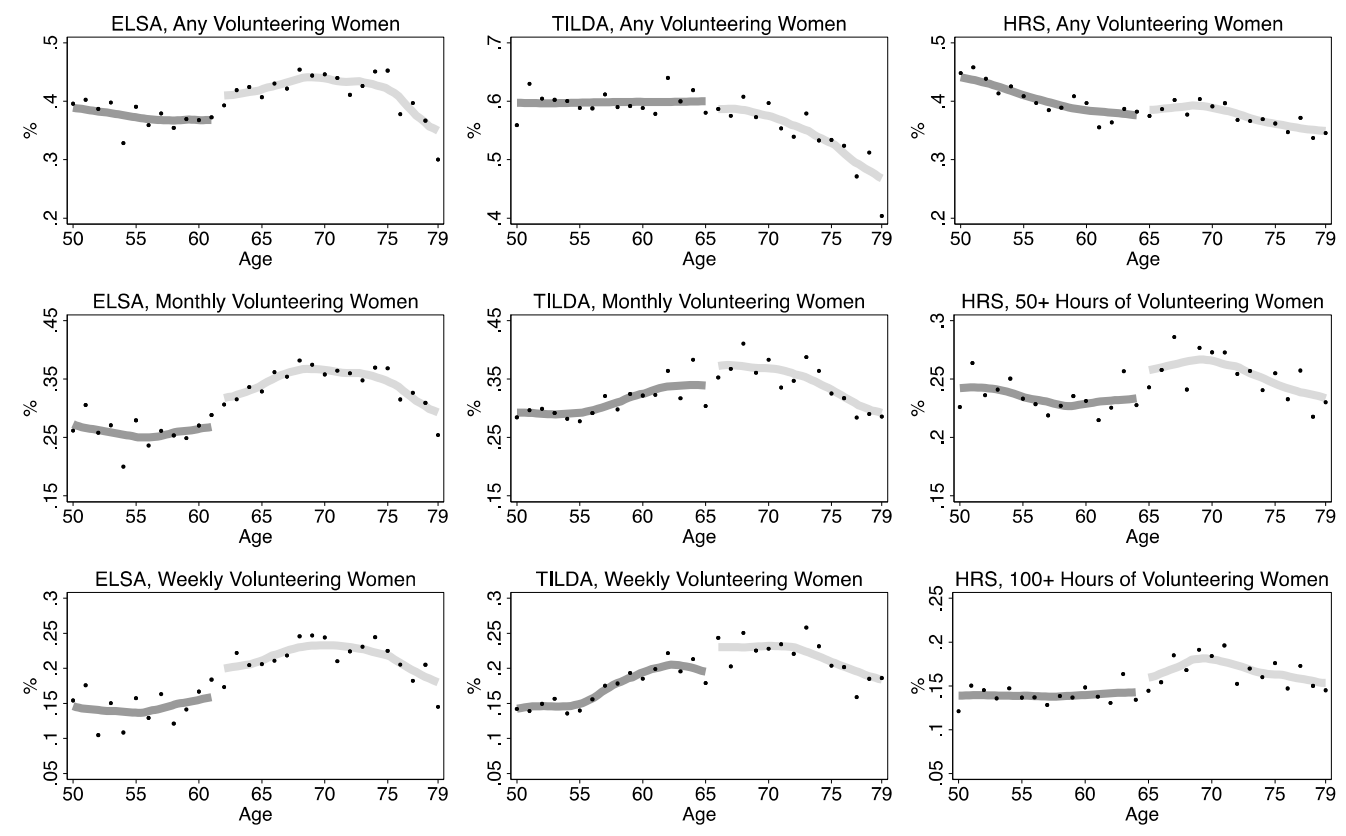

Below SPA

Aggregate means

Source: ELSA Waves 5-8, TILDA Waves 1-4, HRS Waves 10-13.

In Figure 3, state pension age (SPA) is defined as age 62 for England, age 65 for the US and age 66 for Ireland. The grey lines show nonparametric fits based on local mean smoothing. 


\section{Online Appendix}

Table A.1: The effect of retirement on voluntary work

ELSA

TILDA

HRS

Any At least monthly At least weekly Any At least monthly At least weekly

Any $50+$ hours $100+$ hours

\begin{tabular}{|c|c|c|c|c|c|c|c|c|c|}
\hline \multicolumn{10}{|c|}{ A. Men } \\
\hline & $(0.053)$ & $(0.050)$ & $(0.043)$ & $(0.059)$ & (0.057) & $(0.048)$ & $(0.061)$ & $(0.053)$ & $(0.045)$ \\
\hline Wald F & 391.1 & 391.1 & 391.1 & 353.7 & 353.7 & 353.7 & 262.8 & 262.8 & 262.8 \\
\hline $\mathrm{N}$ & 11,718 & 11,718 & 11,718 & 9,318 & 9,318 & 9,318 & 26,275 & 26,275 & 26,275 \\
\hline Retired & $0.183^{* *}$ & $0.242^{* * *}$ & $0.184 * * *$ & 0.110 & $0.220^{*}$ & 0.108 & $0.139 * *$ & $0.182^{* * *}$ & $0.123 * *$ \\
\hline & $(0.068)$ & $(0.064)$ & $(0.053)$ & $(0.094)$ & $(0.092)$ & $(0.078)$ & $(0.054)$ & $(0.048)$ & $(0.040)$ \\
\hline Wald F & 225.3 & 225.3 & 225.3 & 145.0 & 145.0 & 145.0 & 347.1 & 347.1 & 347.1 \\
\hline $\mathrm{N}$ & 13,860 & 13,860 & 13,860 & 10,832 & 10,832 & 10,832 & 34,607 & 34,607 & 34,607 \\
\hline
\end{tabular}

Source: ELSA Waves 5-8, TILDA Waves 1-4, HRS Waves 10-13. Estimates come from a 2SLS regression model controlling for quadratic age, education, ethnicity (except in TILDA), partnership status and survey wave. ELSA and TILDA results use state pension ages as instruments. HRS results use age thresholds at 62 and 65 as instruments.

Clustered standard errors on the individual-level in parentheses. Significance: $\dagger p<0.1, * p<0.05, * * p<0.01, * * * p<0.001$ 
Table A.2: Robustness checks, Men

\begin{tabular}{|c|c|c|c|c|c|c|c|c|c|}
\hline \multirow[b]{2}{*}{ Robustness Check } & \multicolumn{3}{|c|}{ ELSA } & \multicolumn{3}{|c|}{ TILDA } & \multicolumn{3}{|c|}{ HRS } \\
\hline & Any & $\begin{array}{l}\text { At least } \\
\text { monthly }\end{array}$ & $\begin{array}{l}\text { At least } \\
\text { weekly }\end{array}$ & Any & $\begin{array}{l}\text { At least } \\
\text { monthly }\end{array}$ & $\begin{array}{l}\text { At least } \\
\text { weekly }\end{array}$ & Any & $\begin{array}{c}50+ \\
\text { hours }\end{array}$ & $\begin{array}{l}100+ \\
\text { hours }\end{array}$ \\
\hline $\begin{array}{c}\text { Homemakers are not } \\
\text { retired }\end{array}$ & $\begin{array}{c}0.089 \\
(0.054)\end{array}$ & $\begin{array}{l}0.108 * \\
(0.050)\end{array}$ & $\begin{array}{c}0.143 * * * \\
(0.043)\end{array}$ & $\begin{array}{c}0.049 \\
(0.061)\end{array}$ & $\begin{array}{l}0.114^{*} \\
(0.058)\end{array}$ & $\begin{array}{l}0.164^{* * *} \\
(0.049)\end{array}$ & $\begin{array}{l}0.166 * * \\
(0.064)\end{array}$ & $\begin{array}{c}0.182 * * \\
(0.056)\end{array}$ & $\begin{array}{c}0.181^{* * *} \\
(0.047)\end{array}$ \\
\hline $\begin{array}{l}\text { Unemployed are } \\
\text { retired }\end{array}$ & $\begin{array}{c}0.095 \\
(0.058)\end{array}$ & $\begin{array}{l}0.115^{*} \\
(0.054)\end{array}$ & $\begin{array}{c}0.153^{* * *} \\
(0.046)\end{array}$ & $\begin{array}{c}0.062 \\
(0.077)\end{array}$ & $\begin{array}{l}0.143^{*} \\
(0.073)\end{array}$ & $\begin{array}{l}0.205^{* * *} \\
(0.062)\end{array}$ & $\begin{array}{l}0.182 * * \\
(0.070)\end{array}$ & $\begin{array}{l}0.199 * * \\
(0.061)\end{array}$ & $\begin{array}{c}0.198 * * * \\
(0.051)\end{array}$ \\
\hline $\begin{array}{l}\text { Permanently sick or } \\
\text { disabled are retired }\end{array}$ & $\begin{array}{c}0.11 \\
(0.067)\end{array}$ & $\begin{array}{l}0.133^{*} \\
(0.062)\end{array}$ & $\begin{array}{c}0.176 * * \\
(0.053)\end{array}$ & $\begin{array}{c}0.064 \\
(0.079)\end{array}$ & $\begin{array}{l}0.148^{*} \\
(0.075)\end{array}$ & $\begin{array}{l}0.211^{* * *} \\
(0.064)\end{array}$ & $\begin{array}{l}0.180^{*} \\
(0.070)\end{array}$ & $\begin{array}{c}0.198 * * \\
(0.061)\end{array}$ & $\begin{array}{c}0.197 * * * \\
(0.051)\end{array}$ \\
\hline Age range 55-74 & $\begin{array}{l}0.122 \dagger \\
(0.067)\end{array}$ & $\begin{array}{c}0.095 \\
(0.063)\end{array}$ & $\begin{array}{c}0.152^{* *} \\
(0.055)\end{array}$ & $\begin{array}{c}0.030 \\
(0.076)\end{array}$ & $\begin{array}{c}0.049 \\
(0.072)\end{array}$ & $\begin{array}{c}0.124^{*} \\
(0.062)\end{array}$ & $\begin{array}{c}0.206^{*} \\
(0.097)\end{array}$ & $\begin{array}{c}0.229 * * \\
(0.085)\end{array}$ & $\begin{array}{c}0.184 * * \\
(0.071)\end{array}$ \\
\hline Cubic age trend & $\begin{array}{c}0.169 * \\
(0.080)\end{array}$ & $\begin{array}{l}0.129 \dagger \\
(0.075)\end{array}$ & $\begin{array}{c}0.175^{* *} \\
(0.065)\end{array}$ & $\begin{array}{c}0.043 \\
(0.089)\end{array}$ & $\begin{array}{c}0.053 \\
(0.084)\end{array}$ & $\begin{array}{c}0.120^{* * * *} \\
(0.071)\end{array}$ & $\begin{array}{c}0.117 \\
(0.119)\end{array}$ & $\begin{array}{c}0.143 \\
(0.104)\end{array}$ & $\begin{array}{c}0.127 \\
(0.086)\end{array}$ \\
\hline Quartic age trend & $\begin{array}{l}0.171 * \\
(0.083)\end{array}$ & $\begin{array}{c}0.126 \\
(0.077)\end{array}$ & $\begin{array}{c}0.176 * * \\
(0.067)\end{array}$ & $\begin{array}{c}0.036 \\
(0.088)\end{array}$ & $\begin{array}{c}0.045 \\
(0.083)\end{array}$ & $\begin{array}{c}0.120^{* * * *} \\
(0.070)\end{array}$ & $\begin{array}{l}0.167 \\
(0.13)\end{array}$ & $\begin{array}{l}0.191 \\
(0.11)\end{array}$ & $\begin{array}{c}0.167 \dagger \\
(0.093)\end{array}$ \\
\hline Individual FE & $\begin{array}{l}0.133^{*} \\
(0.056)\end{array}$ & $\begin{array}{l}0.109 * \\
(0.052)\end{array}$ & $\begin{array}{l}0.111^{*} \\
(0.048)\end{array}$ & $\begin{array}{c}0.098 \\
(0.071)\end{array}$ & $\begin{array}{l}0.164^{*} \\
(0.069)\end{array}$ & $\begin{array}{c}0.222^{* * *} \\
(0.060)\end{array}$ & $\begin{array}{c}0.137^{*} \\
(0.057)\end{array}$ & $\begin{array}{c}0.108 * \\
(0.052)\end{array}$ & $\begin{array}{l}0.114^{*} \\
(0.045)\end{array}$ \\
\hline
\end{tabular}

Source: ELSA Waves 5-8, TILDA Waves 1-4, HRS Waves 10-13. Estimates come from a 2SLS regression model controlling for quadratic age and survey wave. HRS results use age thresholds at 62 and 65 as instruments, ELSA and TILDA results use state pension ages as instruments. Clustered standard errors on the individual-level in parentheses.

Significance: $\dagger \mathrm{p}<0.1, * \mathrm{p}<0.05, * * \mathrm{p}<0.01, * * * \mathrm{p}<0.001$. 
Table A.3: Robustness checks, Women

\begin{tabular}{|c|c|c|c|c|c|c|c|c|c|}
\hline \multirow[b]{2}{*}{ Robustness Check } & \multicolumn{3}{|c|}{ ELSA } & \multicolumn{3}{|c|}{ TILDA } & \multicolumn{3}{|c|}{ HRS } \\
\hline & Any & $\begin{array}{l}\text { At least } \\
\text { monthly }\end{array}$ & $\begin{array}{l}\text { At least } \\
\text { weekly }\end{array}$ & Any & $\begin{array}{l}\text { At least } \\
\text { monthly }\end{array}$ & $\begin{array}{l}\text { At least } \\
\text { weekly }\end{array}$ & Any & $\begin{array}{c}50+ \\
\text { hours }\end{array}$ & $\begin{array}{l}\text { 100+ } \\
\text { hours }\end{array}$ \\
\hline $\begin{array}{c}\text { Homemakers are not } \\
\text { retired }\end{array}$ & $\begin{array}{l}0.140^{*} \\
(0.061)\end{array}$ & $\begin{array}{c}0.193 * * * \\
(0.057)\end{array}$ & $\begin{array}{l}0.145^{* *} \\
(0.047)\end{array}$ & $\begin{array}{c}0.046 \\
(0.088)\end{array}$ & $\begin{array}{l}0.167^{*} \\
(0.085)\end{array}$ & $\begin{array}{c}0.083 \\
(0.072)\end{array}$ & $\begin{array}{l}0.151^{* *} \\
(0.051)\end{array}$ & $\begin{array}{c}0.181^{* * *} \\
(0.045)\end{array}$ & $\begin{array}{l}0.119 * * \\
(0.037)\end{array}$ \\
\hline $\begin{array}{l}\text { Unemployed are } \\
\text { retired }\end{array}$ & $\begin{array}{l}0.170^{*} \\
(0.075)\end{array}$ & $\begin{array}{c}0.234 * * * \\
(0.070)\end{array}$ & $\begin{array}{c}0.176^{* *} \\
(0.057)\end{array}$ & $\begin{array}{l}0.055 \\
(0.11)\end{array}$ & $\begin{array}{l}0.198^{*} \\
(0.10)\end{array}$ & $\begin{array}{c}0.098 \\
(0.085)\end{array}$ & $\begin{array}{l}0.156^{* *} \\
(0.053)\end{array}$ & $\begin{array}{c}0.187^{* * *} \\
(0.046)\end{array}$ & $\begin{array}{l}0.122 * * \\
(0.038)\end{array}$ \\
\hline $\begin{array}{l}\text { Permanently sick or } \\
\text { disabled are retired }\end{array}$ & $\begin{array}{l}0.195^{*} \\
(0.087)\end{array}$ & $\begin{array}{l}0.268 * * \\
(0.082)\end{array}$ & $\begin{array}{l}0.202 * * \\
(0.066)\end{array}$ & $\begin{array}{l}0.059 \\
(0.11)\end{array}$ & $\begin{array}{c}0.214^{* * * *} \\
(0.11)\end{array}$ & $\begin{array}{c}0.106 \\
(0.092)\end{array}$ & $\begin{array}{l}0.161^{* *} \\
(0.055)\end{array}$ & $\begin{array}{c}0.193 * * * \\
(0.048)\end{array}$ & $\begin{array}{l}0.127^{* *} \\
(0.039)\end{array}$ \\
\hline Age range 55-74 & $\begin{array}{c}0.09 \\
(0.109)\end{array}$ & $\begin{array}{c}0.166 \\
(0.102)\end{array}$ & $\begin{array}{l}0.149 \dagger \\
(0.085)\end{array}$ & $\begin{array}{l}-0.076 \\
(0.13)\end{array}$ & $\begin{array}{l}0.078 \\
(0.13)\end{array}$ & $\begin{array}{l}-0.007 \\
(0.11)\end{array}$ & $\begin{array}{c}0.133 \\
(0.087)\end{array}$ & $\begin{array}{l}0.210 * * \\
(0.077)\end{array}$ & $\begin{array}{l}0.110 \dagger \\
(0.063)\end{array}$ \\
\hline Cubic age trend & $\begin{array}{c}0.036 \\
(0.093)\end{array}$ & $\begin{array}{c}0.117 \\
(0.087)\end{array}$ & $\begin{array}{c}0.098 \\
(0.072)\end{array}$ & $\begin{array}{l}-0.168 \\
(0.18)\end{array}$ & $\begin{array}{l}0.059 \\
(0.17)\end{array}$ & $\begin{array}{l}-0.024 \\
(0.15)\end{array}$ & $\begin{array}{c}0.070 \\
(0.103)\end{array}$ & $\begin{array}{l}0.154 \dagger \\
(0.091)\end{array}$ & $\begin{array}{c}0.018 \\
(0.075)\end{array}$ \\
\hline Quartic age trend & $\begin{array}{c}0.065 \\
(0.121)\end{array}$ & $\begin{array}{c}0.127 \\
(0.113)\end{array}$ & $\begin{array}{c}0.114 \\
(0.094)\end{array}$ & $\begin{array}{l}-0.169 \\
(0.17)\end{array}$ & $\begin{array}{l}0.063 \\
(0.16)\end{array}$ & $\begin{array}{l}-0.016 \\
(0.14)\end{array}$ & $\begin{array}{l}0.0887 \\
(0.12)\end{array}$ & $\begin{array}{l}0.231 \\
(0.11)\end{array}$ & $\begin{array}{c}0.089 \\
(0.086)\end{array}$ \\
\hline Individual FE & $\begin{array}{c}0.135 \\
(0.086)\end{array}$ & $\begin{array}{c}0.217 * * \\
(0.083)\end{array}$ & $\begin{array}{c}0.221^{* *} \\
(0.072)\end{array}$ & $\begin{array}{c}0.002 \\
(0.078)\end{array}$ & $\begin{array}{c}0.073 \\
(0.078)\end{array}$ & $\begin{array}{c}0.072 \\
(0.070)\end{array}$ & $\begin{array}{c}0.203^{* *} \\
(0.062)\end{array}$ & $\begin{array}{c}0.155^{* *} \\
(0.056)\end{array}$ & $\begin{array}{c}0.067 \\
(0.048)\end{array}$ \\
\hline
\end{tabular}

Source: ELSA Waves 5-8, TILDA Waves 1-4, HRS Waves 10-13. Estimates come from a 2SLS regression model controlling for quadratic age and survey wave. HRS results use age thresholds at 62 and 65 as instruments, ELSA and TILDA results use state pension ages as instruments. Clustered standard errors on the individual-level in parentheses.

Significance: $\dagger \mathrm{p}<0.1, * \mathrm{p}<0.05, * * \mathrm{p}<0.01$, *** $\mathrm{p}<0.001$. 